\title{
Hysteropreservation versus hysterectomy in the surgical treatment of uterine prolapse: systematic review and meta-analyses
}

\author{
Sofia Andrade de Oliveira ${ }^{1,2}$ - Maria A. T. Bortolini ${ }^{1}$. Rodrigo A. Castro ${ }^{1}$
}

Received: 12 September 2017 / Accepted: 18 September 2017 /Published online: 7 October 2017

(C) The International Urogynecological Association 2017

\section{Dear Editor,}

We thank the International UrogynecologyJournal for the opportunity to discuss in depth the results of our meta-analysis "Hysteropreservation versus hysterectomy in the surgical treatment of uterine prolapse" [1]. As well-observed by Kapoor et al. in their letter to the editor, we acknowledge the non-inclusion of the trial by Detollenaere et al. [2], even though the authors have evaluated surgical techniques that compared removing and preserving the uterus, the subject of our meta-analysis [1]. Here are some clarifications on this matter.

We conducted our meta-analysis focusing mainly on cases of moderate and advanced uterine prolapse. We used strict criteria for inclusion and for the primary outcomes, different from the meta-analysis designed by Kapoor et al. [3]. We chose $\mathrm{POP} \geq$ stage II with point $\mathrm{C}>0$ as an inclusion criterion.

After careful evaluation of the meta-analysis by Detollenaere et al. [2], we noticed that about $42-48 \%$ of the included participants had point $\mathrm{C}>0$, that is, at least half of the women had apical prolapse that did not reach the hymen, making it difficult to match it even with the Baden-Walker classification.

Detollenaere et al. reported various definitions for failure, single or composite. One of their secondary outcomes in-

This reply refers to the comment available at https://oi.org/10.1007/ s00192-017-3484-3

Sofia Andrade de Oliveira

sofia.gineco@gmail.com

1 Department of Gynecology, Federal University of São Paulo, São Paulo, Brazil

2 Avenida Oceânica, 1454 Ap 19B, Salvador, BA 40170-010, Brazil volved similar criteria for failure as those standardized by us: point $\mathrm{C}>0$ [2], data that could theoretically be used in our meta-analysis [1]. However, the interpretation of the failure rate could be biased considering the inclusion of a high number of women with less advanced POP. The latter may explain the very low failure rate using both techniques found by the authors [2].

Attempts to obtain partial data only from the participants with more advanced POP (point $\mathrm{C}$ beyond the hymen) included in the study by Detollenaere et al. [2] had failed during our study selection. For the reasons mentioned, we did not consider it appropriate to include them in our meta-analysis.

In this way, the different study design among the metaanalyses by Oliveira et al. [1] and Kapoor et al. [3] justifies the contradictory conclusion considering failure rate when comparing sacrospinous hysteropexy with vaginal hysterectomy, both repaired with native tissue, for the management of uterine prolapse.

\section{References}

1. De Oliveira SA, Fonseca MCM, Bortolini MAT, Girão MJBC, Roque MT, Castro RA. Hysteropreservation versus hysterectomy in the surgical treatment of uterine prolapse: systematic review and meta-analysis. Int Urogynecol J. 2017. https://doi.org/10.1007/ s00192-017-3433-1.

2. Detollenaere RJ, den Boon J, Stekelenburg J, IntHout J, Vierhout ME, Kluivers KB, et al. Sacrospinous hysteropexy versus vaginal hysterectomy with suspension of the uterosacral ligaments in women with uterine prolapse stage 2 or higher: multicentre randomized noninferiority trial. BMJ. 2015;351:h3717. https://doi.org/10.1136/bmj. h3717.

3. Kapoor S, Sivanesan K, Robertson JA, Veerasingham M, Kapoor V. Sacrospinous hysteropexy: review and meta-analysis of outcomes. Int Urogynecol J. 2017;28(9):1285-94. https://doi.org/10.1007/ s00192- 017-32914. 